\title{
DYNAMICS OF POLLEN RELEASE AND STIGMATIC EXPOSURE IN NEOTROPICAL PIPER SPECIES: A POSSIBLE PATTERN FOR THE GENUS
}

\author{
Adriano Valentin-Silva, ${ }^{*}$ Marco Antonio Batalha, + and Elza Guimarães ${ }^{1} \neq$ \\ *Graduate Program of Biological Sciences (Botany), Universidade Estadual Paulista, 18618-689 Botucatu, São Paulo State, Brazil; tDepartment of \\ Botany, Universidade Federal de São Carlos, 13565-905 São Carlos, São Paulo State, Brazil; and ¥Department of Botany, \\ Institute of Biosciences, Universidade Estadual Paulista, Botucatu, 18618-689 Botucatu, São Paulo State, Brazil
}

Editor: Janette Steets

Premise of research. Dichogamy is a common feature in early-divergent angiosperms, as in Piper, and is related to the effectiveness of pollination. To better understand the sexual reproduction in Piper species, we determined whether there is a pattern of pollen release and stigmatic exposure in Neotropical species of this genus, independent of flower sexuality and the number of stamens and carpels.

Methodology. We studied 16 Neotropical Piper species, which have flowers with different numbers of stamens and carpels. We analyzed the floral events, in the field and in the laboratory, from bud to senescent flowers.

Pivotal results. Twelve species had only bisexual flowers, and four species had bisexual plus staminate flowers. The bisexual flowers of all the analyzed species showed incomplete protogyny: the pistillate phase of flowers lasted from 2 to $7 \mathrm{~d}$, and the bisexual phase lasted from 1 to $9 \mathrm{~d}$. The stigmas were long-lived (4-16 d), and the stigmatic papillae were exposed sequentially and gradually in a basipetal direction, regardless of the number of carpels in the flower. Anther dehiscence was asynchronous and sequential, occurring in one stamen at a time, regardless of the number of stamens and flower sexuality.

Conclusions. The dynamic of floral events (sequential and gradual exposure and senescence of stigmas in a basipetal direction, and asynchronous and sequential pollen release) suggests a pattern for Neotropical Piper species, considering that the analyzed species belong to different clades of the genus. In addition, these characteristics may also represent a pattern for the genus as a whole, as the floral development and morphology of bisexual and unisexual flowers are similar.

Keywords: asynchronous pollen release, dichogamy, incomplete protogyny, stigmatic longevity.

\section{Introduction}

Dichogamy, mainly protogyny, is a common feature in earlydivergent angiosperms, is related to the effectiveness of pollination (Endress 2010), and may influence the population genetic diversity ( $\mathrm{Li}$ et al. 2016). Additionally, protogyny may act as an effective mechanism to prevent autogamy in self-compatible species (Lloyd and Webb 1986; Bertin and Newman 1993). Nevertheless, protogyny does not prevent geitonogamy if flowers in distinct phases occur in a plant (Pang and Saunders 2014 and references therein). Because Piper species are pollinated by small insects that search for pollen, and dichogamy is a common feature in this genus (Figueiredo and Sazima 2000; Valentin-Silva 2017), it is essential to know the dynamic of floral events to better understand the sexual reproduction in these species, especially the period when pollen is available to pollinators and the period during which pollen can be deposited on a receptive stigma.

\footnotetext{
1 Author for correspondence; e-mail: eguimaraes@ibb.unesp.br.
}

Manuscript received October 2017; revised manuscript received October 2017; electronically published March 23, 2018.
The genus Piper has pantropical distribution, and species differ in the sexuality of their flowers: Neotropical species have bisexual flowers, and Paleotropical species have unisexual flowers (Jaramillo et al. 2008). However, functionally unisexual flowers (staminate) were observed in different populations of four Neotropical Piper species (Figueiredo and Sazima 2000; ValentinSilva 2017). Despite this, the bisexual and unisexual flowers are morphologically similar: perianthless, protected by a bract, with 1-10 stamens and 3-4 carpels (Jaramillo and Manos 2001; Valentin-Silva 2017).

Most studied species of this genus are protogynous, and stigmas are long-lived (Menon 1949; Martin and Gregory 1962; Figueiredo and Sazima 2000; Valentin-Silva et al. 2015). Information about the exposure mode of stigmatic papillae is restricted to the study of Valentin-Silva et al. (2015), which showed that the stigmatic papillae are exposed sequentially and gradually in a basipetal direction in P. vicosanum Yunck. Ontogenetic studies in Piper species with four and six stamens showed that the lateral pairs of stamens develop simultaneously while the median pair develops sequentially, with the anterior-median stamen being formed before the posterior-median stamen (Tucker 1982). Pollen release also occurs asynchronously, in one stamen at a time, as 
described by Valentin-Silva et al. (2015) in P. vicosanum, a species with four stamens. However, the pollen release of the first two stamens is not simultaneous, differing from the sequence of stamen development proposed by Tucker (1982); the other two stamens release pollen sequentially on subsequent days.

Thus, we aimed to determine whether there was a pattern of pollen release and stigmatic exposure in Neotropical Piper species. We described these floral events in 16 Piper species that have different numbers of stamens and carpels, and we also described the floral events in different floral types (bisexual and staminate flowers). Since bisexual and unisexual flowers of Piper species are similar in floral development and morphology (Tucker 1982; Lei and Liang 1998; Jaramillo et al. 2008), we expected that pollen release and stigmatic exposure would be similar among species and, in species with two floral types, the dynamic of pollen release would be similar between bisexual and staminate flowers.

\section{Material and Methods}

We carried out this study from April 2014 to December 2015 in the Station of Research, Environmental Training, and Education Mata do Paraíso, a forest reserve in Viçosa (lat. 20 47' $-48^{\prime} \mathrm{S}$, long. $\left.42^{\circ} 50^{\prime}-52^{\prime} \mathrm{W}\right)$, Minas Gerais State, in southeastern Brazil. This reserve has 194 ha, from 690 to $870 \mathrm{~m}$ above sea level, and its vegetation is classified as seasonal semideciduous montane forest (Veloso et al. 1991).

We studied 16 Piper species (table 1). Most species have inflorescence of the spike type, with bisexual flowers, sessile, androecium with four stamens, three-carpellate gynoecium (the style is usually absent), with superior ovary, which is uniovular (Yuncker 1972, 1973). The studied species belong to different clades of the genus (table 1), representing all clades of Neotropical species of the genus except for the Enckea clade, which has species with restricted distribution in Central America (Jaramillo et al. 2008). Despite this, the floral morphology of these species is similar to that of the Ottonia clade species (Jaramillo et al. 2008). We deposited voucher specimens in BOTU (table 1).
We used four transects in the area (total of $5 \mathrm{~km}$ ) and marked the individuals that had reproductive structures (inflorescences with floral buds, flowers, or fruits) or inflorescence scars, as suggested by Valentin-Silva and Vieira (2015). When possible, we randomly sampled 15 individuals from all marked plants of each species (table 1) using the sample function of $\mathrm{R}$ (R Core Team 2016) to analyze their flowers in the field with a hand lens $(\times 60$ increase) and in the laboratory under a stereomicroscope (fresh or stored in $70 \%$ ethanol), to verify the presence of different floral types and characterize the dynamics of pollen release and stigmatic exposure. We made daily observations during the flowering period of each species (based on phenology data in Valentin-Silva 2017) in two inflorescences per individual (totaling $640 \mathrm{~h}$ of field observation, or about $40 \mathrm{~h}$ per species). Monitoring the exposure of stigmas, which have papillae only on their ventral surfaces, serves as an indication of stigma receptivity (Valentin-Silva et al. 2015). This information, when associated with the period of pollen release, may help in determining the type of dichogamy, when present.

The floral events of all 16 species were investigated and characterized in the field. As the sequence of events was the same in all of the 16 studied species (which had from two to six stamens), we decided to use the species with the highest number of stamens among the analyzed species ( $P$. amplum; see table 1$)$ to illustrate the sequence of events that happens in all of them. For this, we collected samples of $P$. amplum from flower buds to senescent flowers. We fixed the samples in FAA (formaldehyde, acetic acid, and $50 \%$ ethanol, $1: 1: 18 \mathrm{v} / \mathrm{v} / \mathrm{v}$ ) for $48 \mathrm{~h}$ and then stored them in $70 \%$ ethanol (Johansen 1940). Thereafter, we dehydrated the samples in an ethanol series and subjected them to critical-point drying using $\mathrm{CO}_{2}$ and metal deposition with gold (Robards 1978). We examined and captured images with a scanning electron microscope at the Electron Microscopy Center of the Institute of Biosciences of Botucatu, Universidade Estadual Paulista.

\section{Results}

Twelve species had only bisexual flowers, and four species had bisexual plus staminate flowers. The dynamic of floral events was

Table 1

Piper Species Studied and Clade to Which They Belong, Type of Inflorescence, Number of Stamens and Stigmas in Flower, and Number of Sampled Individuals

\begin{tabular}{|c|c|c|c|c|c|c|}
\hline Species & Clade & Inflorescence & No. stamens & No. stigmas & No. individuals & Voucher specimens \\
\hline P. aduncum L. & Radula & Spike & 4 & 3 & 13 & 32,$180 ; 32,198$ \\
\hline P. amplum Kunth & Radula & Spike & 6 & 3 & 11 & 32,$187 ; 32,194$ \\
\hline P. anisum (Spreng.) Angely & Ottonia & Raceme & 4 & 4 & 12 & 32,188 \\
\hline P. arboreum Aubl. & Macrostachys & Spike & 4 & 3 & 10 & 32,181 \\
\hline P. caldense C. DC. & Peltobryon & Spike & 4 & 3 & 15 & 32,$195 ; 32,201$ \\
\hline P. cernuum Vell. & Macrostachys & Spike & 4 & 3 & 14 & 32,$172 ; 32,200$ \\
\hline P. chimonanthifolium Kunth & Radula & Spike & 4 & 3 & 10 & 32,$196 ; 32,199$ \\
\hline P. corcovadensis (Miq.) C. DC. & Ottonia & Raceme & 4 & 4 & 15 & 32,191 \\
\hline P. crassinervium Kunth & Radula & Spike & 4 & 3 & 11 & 32,$175 ; 32,177$ \\
\hline P. gaudichaudianum Kunth & Radula & Spike & 4 & 3 & 12 & 32,$175 ; 32,177$ \\
\hline P. hispidum $\mathrm{Sw}$. & Radula & Spike & 4 & 3 & 15 & 32,$174 ; 32,184$ \\
\hline P. lucaeanum Kunth & Schilleria & Spike & 3 & 3 & 15 & 32,$182 ; 32,193$ \\
\hline P. malacophyllum (C. Presl) C. DC. & Radula & Spike & 4 & 3 & 10 & 32,$178 ; 32,185$ \\
\hline P. mollicomum Kunth & Radula & Spike & 4 & 3 & 8 & 32,$179 ; 32,190$ \\
\hline P. pubisubmarginalum Yunck. & Schilleria & Spike & 3 & 3 & 15 & 32,192 \\
\hline P. umbellatum L. & Pothomorphe & Umbel of spikes & 2 & 3 & 15 & 32,176 \\
\hline
\end{tabular}




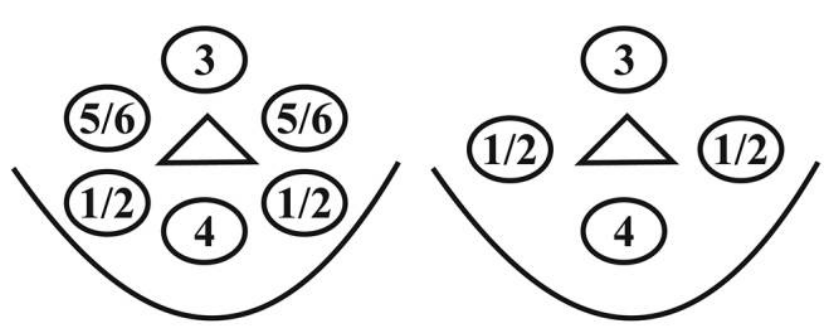

ual flowers (table 2). We observed no changes in the pistillode throughout the anthesis period, and these flowers did not bear fruit.

In bisexual flowers of $P$. amplum, the bract fully covered the androecium and gynoecium during the flower bud stage. As the bract began to open, the apical portion of the anthers of three stamens - stamens 1, 2 (the posterior-lateral pair), and 3 (the anterior-median stamen, located between the first two; fig. $3 A$ ) became visible. At that time, stamen 4 (the posterior-median stamen, located between the bract and the ovary) was still hidden by the bract; stamens 5 and 6 (the anterior-lateral pair) were also not visible. On average, $7 \mathrm{~d}$ after the beginning of bract opening, the juxtaposed and upright stigmas became visible among the stamens (fig. 3B). Stamen 4 became visible, as well as stamens 5 and 6 (fig. $3 B$ ), due to the bract opening.

Anthesis began with the receptivity of the stigmas, characterized by exposure of turgid papillae at the distal portion (located on the ventral surface of stigmas; fig. $3 C$ ), while the median and proximal portions of the stigmas remained juxtaposed. Anthers of all stamens remained indehiscent, so the species was protogynous due to the onset of stigmatic receptivity before pollen release. The pistillate phase of flowers lasted from 2 to $7 \mathrm{~d}$ and varied among flowers of the same individual.

Pollen release began in flowers that still showed receptive stigmas, indicating incomplete protogyny and characterizing the bisexual phase. Pollen was released during the hottest hours of the day, usually between 10:00 a.m. and 2:00 p.m., forming clumps on the anther, which could remain on it for more than $24 \mathrm{~h}$. Stamens 1 and 2 were the first ones to release pollen, but asynchronously. The stamen that released pollen became higher than the other stamen, due to the total exposure of filament and anther; both stamens 1 and 2 can be the first to release pollen. These stamens released pollen on the same day but at different times, with at least $1 \mathrm{~h}$ of difference (figs. 3D, 4). Another observation was the pollen release on consecutive days, usually in the morning, about $24 \mathrm{~h}$ apart (figs. $3 E-3 H, 4)$. On that occasion, the stigmas were farther apart from each other, exposing the papillae of the distal and median portions of the stigmas. Besides, the stigmatic papillae located in the distal portion of the stigmas could be darkened (fig. 3E-3H), indicating the onset of stigmatic senescence on this portion.

One day after pollen release by stamens 1 and 2, the abscission of the anther and part of the filament of these stamens generally

dehiscence was asynchronous and sequential, occurring in one stamen at a time; the pollen release sequence was similar among species, regardless of the number of stamens in the flower (fig. 1). The onset of stigmatic senescence varied, among both species and inflorescences of the same species. We noted that the stigmatic senescence, characterized by darkening of the stigmas, could start at the end of the pistillate phase or during the bisexual phase of the flowers in all 16 investigated species (fig. 2). Therefore, it is possible that intraspecific and interspecific variations occur in the duration of the analyzed floral events but not in their dynamics.

We observed two floral types (bisexual and staminate flowers) in Piper arboreum, $P$. caldense, $P$. cernuum, and P. chimonanthifolium. The functionally unisexual flowers were morphologically similar to bisexual flowers: they had a bract, four stamens with dithecous anthers, and a pistillode (reduced and nonfunctional pistil). In these flowers, the anther dehiscence was also asynchronous and sequential, occurring in one stamen at a time, and the period of pollen release was similar to that observed for the bisex-

Table 2

Duration of Pistillate and Bisexual Phases in the Bisexual Flowers, According to the Number of Stamens in the Flower, and Duration of Anthesis in the Staminate Flowers

\begin{tabular}{lcc}
\hline No. stamens & Pistillate phase & Bisexual phase \\
\hline 6 & $2-7$ & $4-9$ \\
4 & $2-5$ & $3-6$ \\
4 & $\ldots$ & $3-6$ \\
3 & $2-4$ & $2-4$ \\
2 & $3-4$ & $1-2$ \\
\hline
\end{tabular}

Note. Underlining is used to differentiate staminate flowers from bisexual flowers. 

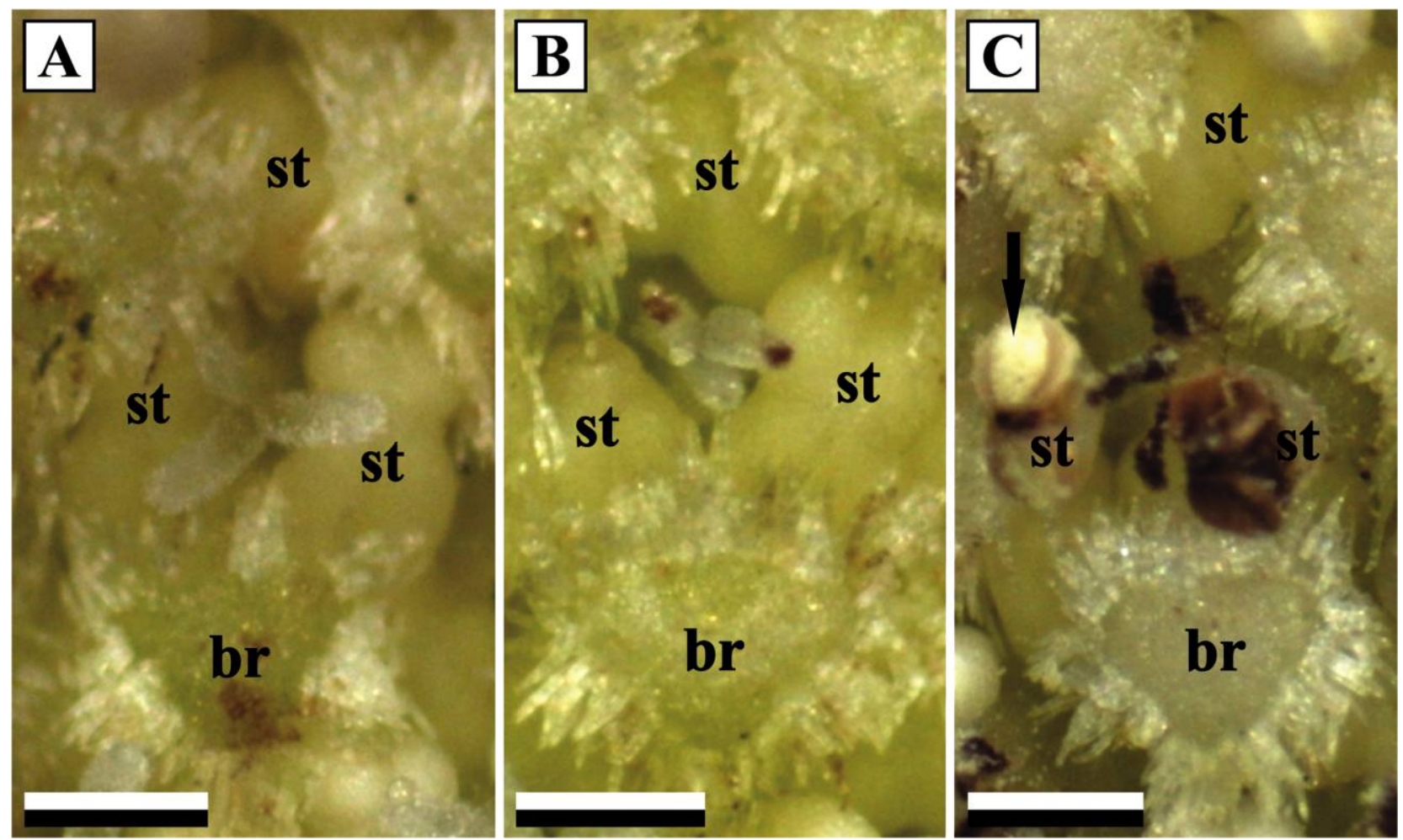

Fig. 2 Stigmatic senescence in Piper chimonantifolium. A, Flower in the pistillate phase; B, onset of stigmatic senescence on distal portion; C, flower in the bisexual phase with partially senescent stigmas; observe an anther releasing pollen (arrow). br $=$ bract; st $=$ stamen. Scale bars $=500 \mu \mathrm{m}$.

occurred (fig. 3I). On that occasion, stamen 3 was more exposed and could release pollen (fig. $5 \mathrm{~A}$ ) or remain indehiscent and release pollen on the subsequent day (fig. 4). The stigmas were almost completely exposed, and the papillae of the distal and median portions were already darkened in part of the flowers in the inflorescence. At this stage, the extent of the stigmas darkened was variable among the flowers.

One day after pollen release by stamen 3 , three stamens with indehiscent anthers remained in the flower (fig. $5 B$ ). On that occasion, stamen 4 could release pollen (fig. $5 \mathrm{C}$ ) or remain indehiscent and release pollen on the subsequent day, presenting a variation similar to that observed for stamen 3 (fig. 4). Stamens 5 and 6 were more visible at this time (fig. 5C) due to the abscission of stamens that already released pollen, and the stigmas usually had nondarkened papillae on just the proximal portion.

One day after pollen release by stamen 4, stamens 5 and 6 were more exposed and could release pollen (fig. $5 D$ ). The variation in pollen release was similar to that observed in stamens 1 and 2 (figs. 4, 5E-5I). At that time, most of the flowers had stigmas that were totally darkened, indicating the end of stigmatic receptivity; however, a few flowers could still have receptive stigmas.

Anther dehiscence asynchrony led to variations in the extension of the pollen release period among the stamens, which may last 4$9 \mathrm{~d}$ (fig. 4). This asynchrony was related to the pollen release by one stamen at a time, on different days. Besides this, there was the possibility of stamens releasing pollen on consecutive days or possibly having an interval of $1 \mathrm{~d}$ until the next stamen released pollen. The combination of these different possibilities is shown in figure 4. After the abscission of stamens 5 and 6 , the stigmas were collapsed. Then, ovary size increased during fruiting (fig. $4 J$ ) if the flower was fertilized.

\section{Discussion}

Incomplete protogyny, as observed here, can favor crosspollination during the pistillate phase of flowers but does not prevent the occurrence of self-pollination during the bisexual phase of flowers (Lloyd and Webb 1986; Bertin and Newman 1993; Endress 2010; Li et al. 2016). Thus, other reproductive mechanisms may be associated with dichogamy, preventing autogamy - self-incompatibility, for example. On the one hand, this combination of incomplete protogyny and self-incompatibility was observed in 13 Piper species in southeastern Brazil (Figueiredo and Sazima 2000; Valentin-Silva 2017). On the other hand, the combination of incomplete protogyny and self-compatibility is also common (11 species; Figueiredo and Sazima 2000; Valentin-Silva 2017). In this case, autogamy or geitonogamy may occur, depending on the visiting behavior of the pollinators (Lloyd and Schoen 1992). Even if dichogamy may vary depending on the environmental conditions and geographical limits of each species (Lloyd and Bawa 1984), the dynamic of floral events can occur in a similar way in these Piper species, as well as in a possible adichogamous species such as $P$. regnellii (Miq.) C. DC. (Figueiredo and Sazima 2000).

Gradual and sequential exposure of stigmatic papillae is related both to the incomplete protogyny and to the longevity of the stigmas (Valentin-Silva et al. 2015), characteristics observed in all analyzed species. Long-lived stigmas are common 

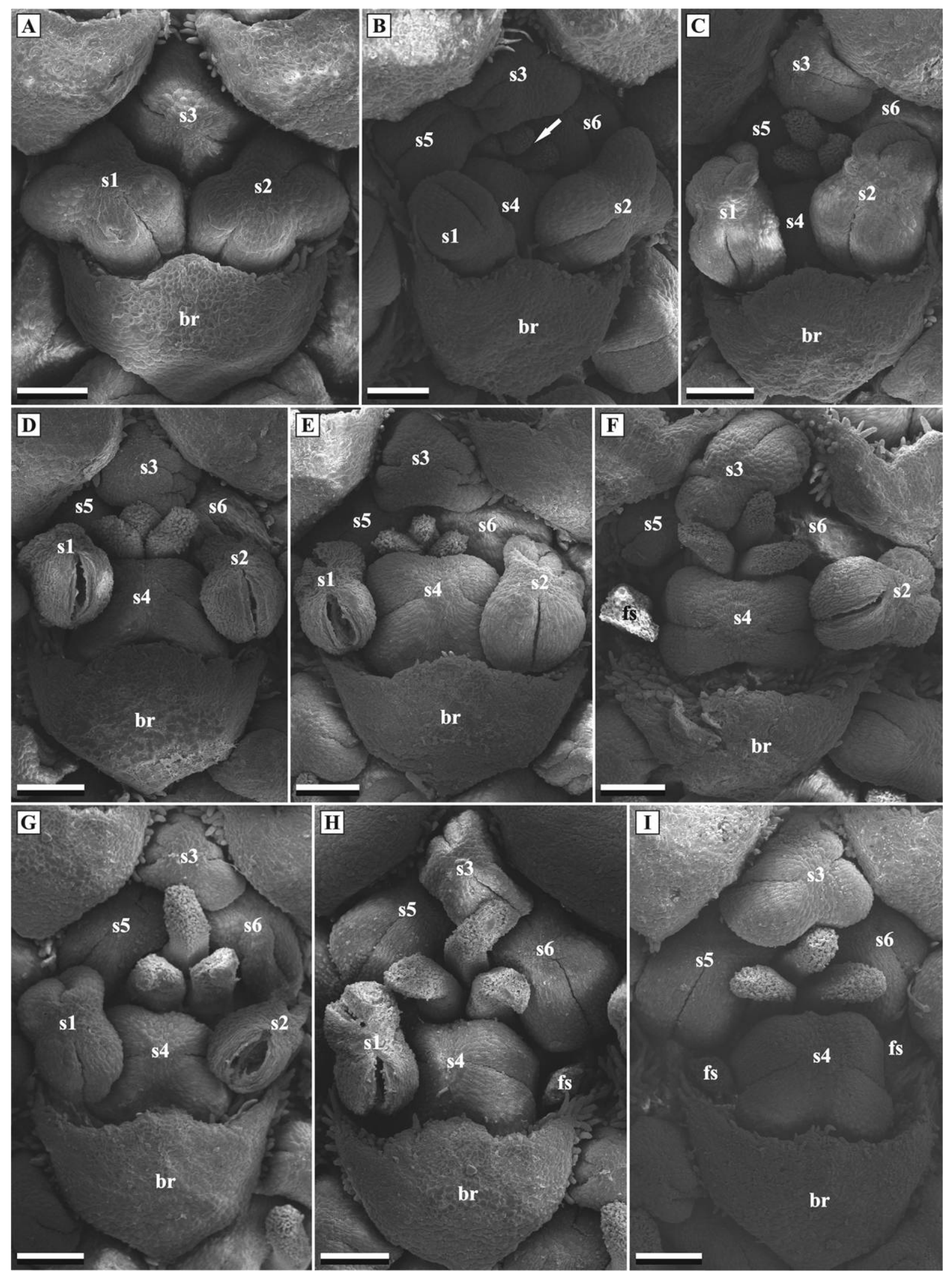

Fig. 3 Flowers of Piper amplum as buds, in the pistillate phase and at the beginning of the bisexual phase. A, Onset of stamens' exposure; $B$, floral bud with stigmas among the anthers (arrow); $C$, partial exposure of the six stamens and the papillae on the distal portion of stigmas; $D$, pollen release by stamens 1 and 2 on the same day; $E, F$, pollen release by stamens 1 and 2 on subsequent days, starting with stamen 1 ; $G, H$, pollen release by stamens 1 and 2 on subsequent days, starting with stamen $2 ; I$, flower after pollen release by stamens 1 and 2 . The bract apex is directed toward the distal region of the spike. $\mathrm{br}=$ bract; fs = filament scar; s1-s6 = stamens 1-6. Scale bars $=200 \mu \mathrm{m}$. 


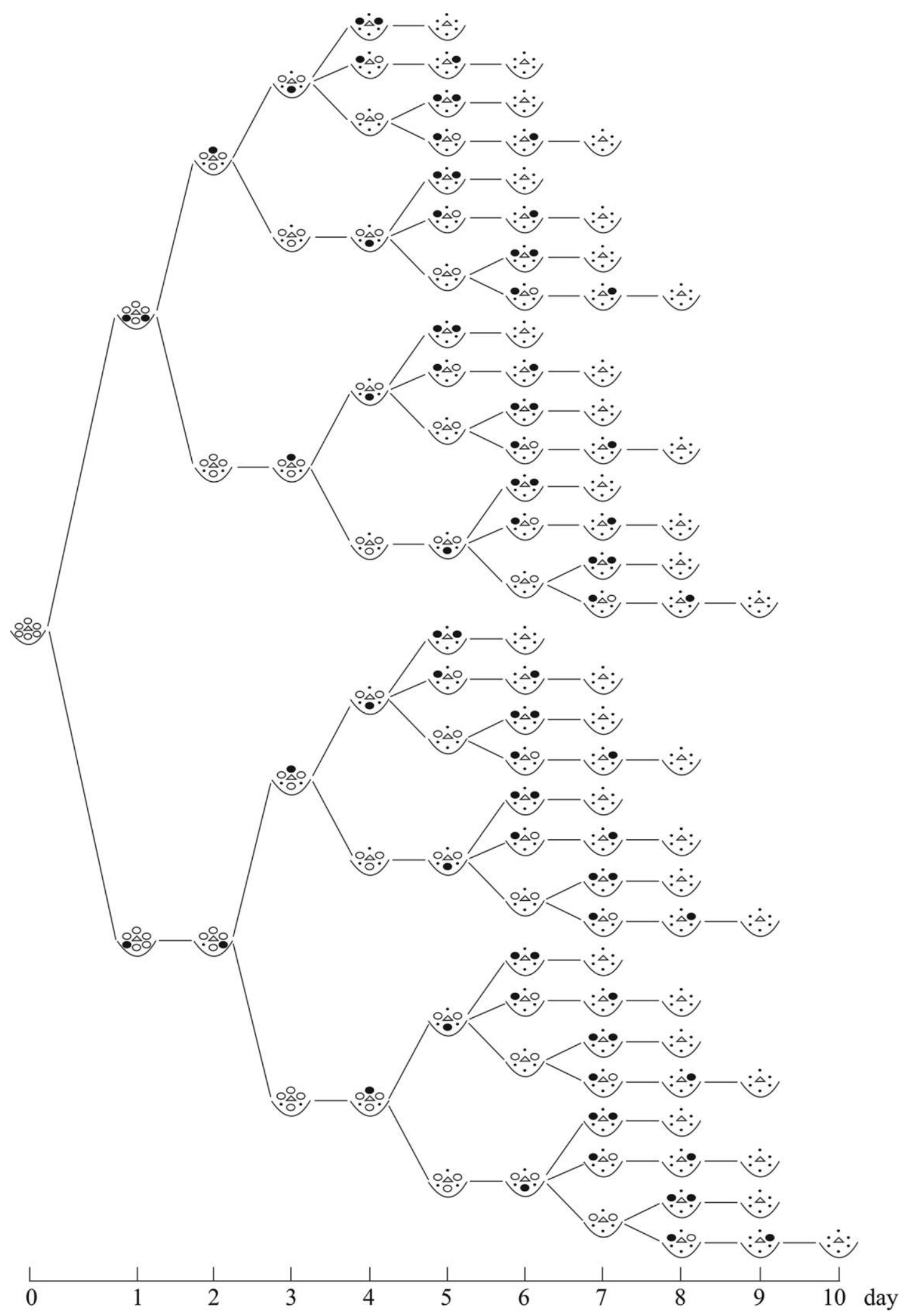

Fig. 4 Diagrams of Piper amplum flowers with all the possible pollen-release sequences from the six stamens. Open circles $=$ indehiscent anther; filled circles $=$ pollen-releasing anther; dots $=$ filament scar; triangles $=$ gynoecium; curved lines $=$ bract. 

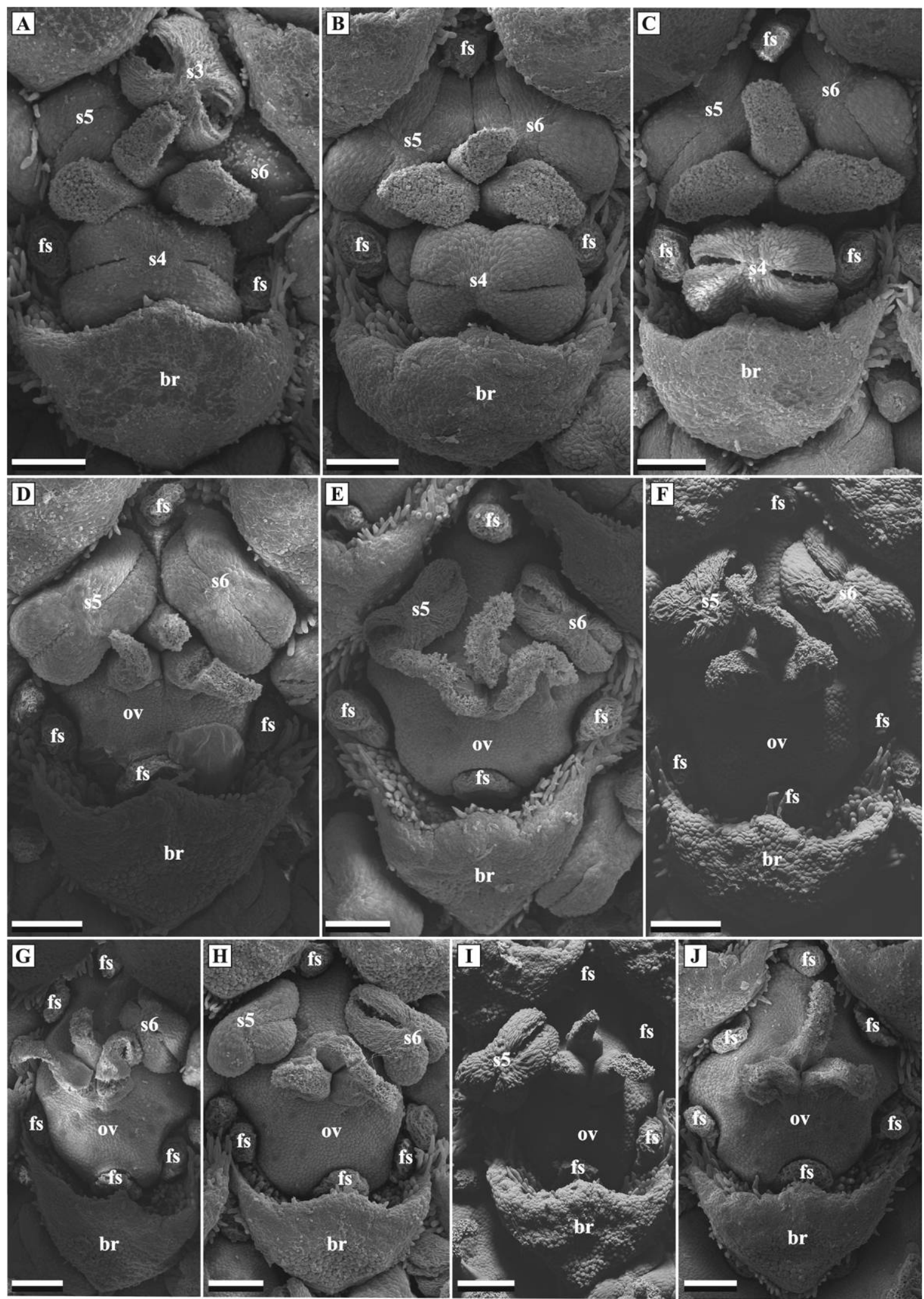

Fig. 5 Flowers of Piper amplum at the end of the bisexual phase. A, Pollen release by stamen 3 and stigmas almost completely exposed; $B$, flower after pollen release by stamen 3 ; $C$, pollen release by stamen 4 and turgid papillae on the proximal portion of stigmas; $D$, flower after pollen release by stamen $4 ; E$, pollen release by stamens 5 and 6 on the same day; $F, G$, pollen release by stamens 5 and 6 on subsequent days, starting with stamen $5 ; H$, I, pollen release by stamens 5 and 6 on subsequent days, starting with stamen 6 (observe the collapsed stigmas); $J$, immature fruit. The bract apex is directed toward the distal region of the spike. br = bract; fs $=$ filament scar; ov $=$ ovary; s3-s6 = stamens $3-$ 6. Scale bars $=200 \mu \mathrm{m}$. 
in Piper species (Figueiredo and Sazima 2000; Valentin-Silva et al. 2015), including the Paleotropical species P. nigrum L. (Menon 1949; Martin and Gregory 1962). This characteristic has been related to the greater probability of stigmas receiving enough pollen grains (Cruden 2000), which may favor sexual reproduction. The mode of exposure for stigmatic papillae also seems to be common in the species of this genus, as demonstrated herein. It was observed in species with four stigmas, the ancestral condition in Piperaceae (Jaramillo et al. 2004), and in species with three stigmas. Based on this, the mode of stigmatic papillae exposure may be phylogenetically conserved because it was independent of the number of carpels in the flower. Furthermore, it is possible that this mode of stigmatic exposure also occurs in the pistillate flowers of Paleotropical Piper species, which have gynoecium development similar to that described for the bisexual flowers of Neotropical species (Lei and Liang 1998).

Due to the sequential and gradual exposure of stigmas, a set of receptive papillae is exposed in a basipetal direction, suggesting that the stigmas are functionally fragmented (Valentin-Silva et al. 2015). Moreover, there seems to be a functional separation between portions of the stigmas. The stigmatic papillae of the distal portion should be associated with pollen received during the pistillate phase of the flower, so coming from other flowers, favoring xenogamy or geitonogamy, depending on the dynamics of opening of flowers in the inflorescence and in the plant. After the onset of the bisexual phase of the flower and the beginning of the stigmatic senescence, which is gradual, the median and proximal portions of the stigmas can receive, in addition to pollen from other plants, their own pollen, featuring self-pollination.

Stigmatic senescence occurred similarly to the exposure of stigmatic papillae, sequentially and gradually in a basipetal direction, as described by Valentin-Silva et al. (2015). The darkening of the stigmas observed in the analyzed species may be related to the accumulation of phenolic compounds, as recorded in $P$. vicosanum (Valentin-Silva et al. 2015). The variation in the time of onset of stigmatic senescence may be related to the pollinator visits to the flowers of each species, considering that stigmas not pollinated may remain receptive for a longer time than pollinated stigmas (Devlin and Stephenson 1984; Richardson and Stephenson 1989).

Pollen release was asynchronous, as it occurred in one stamen at a time, even in the lateral pairs of simultaneously developed stamens (Tucker 1982), and was sequential, coinciding with the bilateral initiation sequence of stamens. Although the number of stamens was homoplastic in Piperales (Jaramillo et al. 2004), the asynchronous and sequential pollen release was observed in all species, similar to that recorded in $P$. vicosanum (ValentinSilva et al.2015), and was independent of the number of stamens in the flower. Nevertheless, the greater the number of stamens on a flower, the longer the pollen release period. Thus, the offering period of floral resource (pollen) is increased, for example, in species with six stamens, which can increase the chances of crosspollination (Li et al. 2016).

Furthermore, pollen release in the four species with staminate flowers was also asynchronous and sequential. This indicates that the asynchrony in pollen release is independent of the presence of the pistil and can also occur in staminate flowers of $\mathrm{Pa}$ leotropical Piper species, which have androecium development similar to that described for the bisexual flowers of Neotropical species (Lei and Liang 1998).

The characteristics observed here (sequential and gradual exposure and senescence of stigmas in a basipetal direction, and asynchronous and sequential pollen release) suggest a pattern for Neotropical Piper species, considering that the analyzed species belong to different clades of the genus. Even though we observed variations in the duration of floral events, the 16 studied species showed no variations in the dynamics of floral events, reinforcing the idea that it represents a pattern for these clades. There are no similar studies with Paleotropical Piper species, so it is not possible to do direct comparisons with these species. Despite this, as the floral development and morphology of bisexual and unisexual flowers are similar between Neotropical and Paleotropical Piper species, the characteristics described herein may represent a pattern for the genus as a whole.

\section{Acknowledgments}

We thank the Coordination for the Improvement of Higher Education Personnel and the Brazilian National Council for Scientific and Technological Development for the scholarships for a doctor's degree and research productivity grant (305912/20135), respectively, to A. Valentin-Silva and M. A. Batalha. We also thank the Electron Microscopy Center of the Institute of Biosciences of Botucatu at the Universidade Estadual Paulista. We are indebted to Elsie Franklin Guimarães and Micheline Carvalho-Silva for their assistance with plant identification.

\section{Literature Cited}

Bertin RI, CM Newman 1993 Dichogamy in angiosperms. Bot Rev 59:112-152.

Cruden RW 2000 Pollen grains: why so many? Plant Syst Evol 222: 143-165.

Devlin B, AG Stephenson 1984 Factors that influence the duration of the staminate and pistillate phases of Lobelia cardinalis flowers. Bot Gaz 145:323-328.

Endress PK 2010 The evolution of floral biology in basal angiosperms. Philos Trans R Soc B 365:411-421.

Figueiredo RA, M Sazima 2000 Pollination biology of Piperaceae species in southeastern Brazil. Ann Bot 85:455-460.

Jaramillo MA, R Callejas, C Davidson, JF Smith, AC Stevens, E Tepe 2008 A phylogeny of the tropical genus Piper using ITS and the chloroplast intron psbJ-petA. Syst Bot 33:647-660.
Jaramillo MA, P Manos 2001 Phylogeny and patterns of floral diversity in the genus Piper (Piperaceae). Am I Bot 88:706-716.

Jaramillo MA, PS Manos, EA Zimmer 2004 Phylogenetic relationships of the perianthless Piperales: reconstructing the evolution of floral development. Int I Plant Sci 165:403-416.

Johansen DA 1940 Plant microtechnique. McGraw-Hill, New York.

Lei LG, HX Liang 1998 Floral development of dioecious species and trends of floral evolution in Piper sensu lato. Bot J Linn Soc 127: 225-237.

Li PS, CC Pang, RMK Saunders 2016 Contrasting pollination ecology of Disepalum species (Annonaceae): evolutionary loss of the floral chamber and partial breakdown of protogyny associated with a shift in pollination system. Bot I Linn Soc 182:708-718. 
Lloyd DG, KS Bawa 1984 Modification of the gender of seed plants in varying conditions. Evol Biol 17:255-338.

Lloyd DG, DJ Schoen 1992 Self- and cross-fertilization in plants. I. Functional dimensions. Int I Plant Sci 153:358-369.

Lloyd DG, CJ Webb 1986 The avoidance of interference between the presentation of pollen stigmas in angiosperms I. Dichogamy. N Z I Bot 24:135-162.

Martin FW, LE Gregory 1962 Mode of pollination and factors affecting fruit set in Piper nigrum L. in Puerto Rico. Crop Sci 2: 295-299.

Menon KK 1949 The survey of pollu and root diseases of pepper. Indian J Agric Sci 19:89-136.

Pang CC, RMK Saunders 2014 The evolution of alternative mechanisms that promote outcrossing in Annonaceae, a self-compatible family of early-divergent angiosperms. Bot I Linn Soc 174:93109.

R Core Team 2016 R: a language and environment for statistical computing. R Foundation for Statistical Computing, Vienna. https://www .R-project.org/.

Richardson TE, AG Stephenson 1989 Pollen removal and pollen deposition affect the duration of the staminate and pistillate phases in Campanula rapunculoides. Am I Bot 76:532-538.
Robards AW 1978 An introduction to techniques for scanning electron microscopy of plant cells. Pages 343-403 in JL Hall, ed. Electron microscopy and cytochemistry of plant cells. Elsevier, New York.

Tucker SC 1982 Inflorescence and flower development in the Piperaceae. III. Floral ontogeny of Piper. Am I Bot 69:1389-1401.

Valentin-Silva A 2017 Fenologia e biologia reprodutiva de espécies de Piper (Piperaceae) em floresta estacional semidecídua: aspectos ecológicos e filogenéticos. PhD diss. Universidade Estadual Paulista, Botucatu, São Paulo.

Valentin-Silva A, VPM Coelho, MC Ventrella, MF Vieira 2015 Timing of pollen release and stigma receptivity period of Piper vicosanum (Piperaceae): new insights into sexual reproduction of the genus. Am I Bot 102:626-633.

Valentin-Silva A, MF Vieira 2015 Phenology of two co-occurring Piper (Piperaceae) species in Brazil. Aust I Bot 63:581-589.

Veloso HP, ALR Rangel-Filho, JCA Lima 1991 Classificação da vegetação brasileira, adaptada a um sistema universal. Instituto Brasileiro de Geografia e Estatística, Rio de Janeiro.

Yuncker TG 1972 The Piperaceae of Brazil. I. Piper: group I, II, III, IV. Hoehnea 2:19-366.

1973 The Piperaceae of Brazil. II. Piper: group V; Ottonia; Pothomorphe; Sarcorhachis. Hoehnea 3:29-284. 